\title{
Effect of Solution Treatment on Microstructure and Corrosion Properties of Mg-4Gd-1Y-1Zn-0.5Ca-1Zr Alloy
}

\author{
Jian-Wei Dai ${ }^{1,2} \cdot$ Xiao-Bo Zhang ${ }^{1,2} \cdot$ Yang Fei $^{1,2} \cdot$ Zhang-Zhong Wang $^{1,2} \cdot$ Huai-Ming Sui $^{3}$ \\ Received: 9 November 2017 / Revised: 15 December 2017/Published online: 6 February 2018 \\ (C) The Chinese Society for Metals and Springer-Verlag GmbH Germany, part of Springer Nature 2018
}

\begin{abstract}
The as-cast multi-element $\mathrm{Mg}-4 \mathrm{Gd}-1 \mathrm{Y}-1 \mathrm{Zn}-0.5 \mathrm{Ca}-1 \mathrm{Zr}$ alloy with low rare earth additions was prepared, and the solution treatment was applied at different temperatures. The microstructural evolution of the alloy was characterized by optical microscopy and scanning electron microscopy, and corrosion properties of the alloy in $3.5 \% \mathrm{NaCl}$ solution were evaluated by immersion and electrochemical tests. The results indicate that the as-cast alloy is composed of the $\alpha-\mathrm{Mg}$ matrix, lamellar long-period stacking-ordered (LPSO) structure and eutectic phase. The LPSO structure exists with more volume fraction in the alloy solution-treated at $440{ }^{\circ} \mathrm{C}$, but disappears with the increase in the solution temperature. For all the solution-treated alloys, the precipitated phases are detected. The corrosion rates of the alloys decrease first and then increase slightly with the increase in the solution temperature, and the corrosion resistance of the solution-treated alloys is more than four times as good as that of the as-cast alloy. In addition, the alloy solution-treated at $480{ }^{\circ} \mathrm{C}$ for $6 \mathrm{~h}$ shows the best corrosion property.
\end{abstract}

Keywords Magnesium alloy $\cdot$ Solution treatment $\cdot$ Microstructure $\cdot$ Corrosion properties

\section{Introduction}

Magnesium $(\mathrm{Mg})$ alloys are recognized as desirable lightweight materials mainly owing to their overall superior properties, such as low density, high specific strength, good castability and better damping capacity [1-3]. And the potential applications of $\mathrm{Mg}$ alloys in the industries, including the automotive and aerospace industries, contribute to the fuel economy since the greater use of lowdensity $\mathrm{Mg}$ alloys can lead to the additional weight reductions compared with high-strength steels, aluminum alloys and composites $[4,5]$. However, it has been previously proved that $\mathrm{Mg}$ alloys showed relatively low strength

Available online at http://link.springer.com/journal/40195

Xiao-Bo Zhang

xbxbzhang2003@163.com

1 School of Materials Science and Engineering, Nanjing Institute of Technology, Nanjing 211167, China

2 Jiangsu Key Laboratory of Advanced Structural Materials and Application Technology, Nanjing 211167, China

3 Yangzhou Fengming Optronic New Material Co., Ltd, Yangzhou 225117, China and ductility [6, 7]. Furthermore, too fast corrosion was also one of the most limitations for the wide applications of $\mathrm{Mg}$ alloys since $\mathrm{Mg}$ is a chemically active element and it is susceptible to the aqueous environment, especially containing $\mathrm{Cl}^{-}$solution $[8,9]$.

To overcome these drawbacks, extensive studies have been carried out to enhance the mechanical properties and corrosion resistance of the $\mathrm{Mg}$ alloys [10-15]. For instance, $\mathrm{Mg}-\mathrm{Al}-\mathrm{Zn}$ series alloys were a category of widely used commercial $\mathrm{Mg}$ alloys, and the mechanical properties of these $\mathrm{Mg}$ alloys were enhanced by the methods of hot extrusion, severe plastic deformation and so on [16-20]. Nevertheless, the appropriate addition of alloying elements, especially rare earth (RE) elements, has become a hot topic for their more direct and beneficial effects on the microstructure evolution and comprehensive property improvements of Mg alloys [21-25]. Recent studies have revealed that $\mathrm{Mg}$ alloys with $\mathrm{RE}$ additions showed refined grain size and novel phases, which were beneficial to the strengths of Mg alloys. But most of these alloys contained high RE additions, and this led to higher cost compared with non-containing RE Mg alloys and/or even unmatched strength and elongation [26, 27]. 
Mg-Gd-Y series alloys have attracted increasing attentions among the RE-containing Mg alloys [28-30]. The mechanical properties of $\mathrm{Mg}-x \mathrm{Gd}-3 \mathrm{Y}-0.5 \mathrm{Zr}$ alloys $(x=3-12 \mathrm{wt} \%)$ under different conditions were investigated. With the increase in the Gd content, the enhanced age hardening response was obtained, and the T6-treated $\mathrm{Mg}-10 \mathrm{Gd}-3 \mathrm{Y}-0.5 \mathrm{Zr}$ alloy showed the best tensile properties due to the presence of $\operatorname{Mg}_{5}(\mathrm{Gd}, \mathrm{Y})$ particles and $\beta^{\prime}$ precipitated phases among the alloys [27]. The effect of the aging treatment on the tensile strength and yield strength was also detected for $\mathrm{Mg}-10 \mathrm{Gd}-\mathrm{Y}-2.5 \mathrm{Nd}-0.5 \mathrm{Zr}$ alloy [30]. It has been reported that long period stacking ordered (LPSO) structure was found in $\mathrm{Mg}-\mathrm{Y}-\mathrm{Zn}[31,32]$ and $\mathrm{Mg}-$ Gd-Zn [33-35] series alloys. This structure has also been observed in $\mathrm{Mg}-\mathrm{Gd}-\mathrm{Y}-\mathrm{Zn}$ series alloys recently [36-39]. Some studies have summarized that the formation, volume fraction and distribution of the LPSO structure were controlled by the content of alloying elements, and the $\mathrm{Mg}$ alloys exhibited good mechanical properties owing to the presence of the LPSO structure [40, 41]. However, the corrosion resistance of the as-cast $\mathrm{Mg}_{94} \mathrm{Zn}_{3} \mathrm{Y}_{x} \mathrm{Gd}_{3-x}$ alloys was immune to the LPSO structure [41], while the corrosion rates of the as-cast $\mathrm{Mg}_{97-x} \mathrm{Zn}_{1} \mathrm{Y}_{2} \mathrm{Gd}_{x}$ alloys decreased due to the increased volume fraction of the LPSO structure [42]. Therefore, it was speculated that the LPSO structure showed positive effect on the mechanical properties of the $\mathrm{Mg}$ alloys but the influence on their corrosion behaviors was not clear.

It was known that the poor corrosion resistance was a major problem that hindered the practical applications of $\mathrm{Mg}$ alloys, which must be solved. Based on the above literatures, the design of LPSO-containing Mg alloys with low RE additions still needs to be further developed. Researchers have reported that zinc $(\mathrm{Zn})$ is an essential element for the formation of the LPSO structure and the addition of $\mathrm{Zn}$ can enhance the corrosion resistance [43]. Calcium $(\mathrm{Ca})$ played a significant role in the grain refinement and the formation of the novel phases, and the alloy with the appropriate content of $\mathrm{Ca}$ has shown a good corrosion performance [44]. And zirconium ( $\mathrm{Zr}$ ) has shown similar impact on the microstructure and corrosion resistance of the Mg alloy [45]. So, with the combination of the beneficial effects of these minor alloying elements on the corrosion properties of the $\mathrm{Mg}$ alloys, the as-cast multielement $\mathrm{Mg}-4 \mathrm{Gd}-1 \mathrm{Y}-1 \mathrm{Zn}-0.5 \mathrm{Ca}-1 \mathrm{Zr}$ alloy with low $\mathrm{RE}$ contents was prepared and solution-treated at different temperatures. The microstructural evolution and corrosion rates under containing $\mathrm{Cl}^{-}$aqueous environment were characterized, aiming at a better understanding of the effect of solution treatment on the alloy and ascertaining its candidate for the industrial applications.

\section{Experimental}

The nominal $\mathrm{Mg}-4 \mathrm{Gd}-1 \mathrm{Y}-1 \mathrm{Zn}-0.5 \mathrm{Ca}-1 \mathrm{Zr}$ alloy was prepared by gravity casting. It was melted by pure $\mathrm{Mg}$ (99.99\%), Mg-30 wt\% Gd, Mg-30 wt\% Y, pure $\mathrm{Zn}$ (99.99\%), Mg-30 wt\% $\mathrm{Ca}$ and $\mathrm{Mg}-30 \mathrm{wt} \% \mathrm{Zr}$ master alloys using an electric resistance furnace under a protective atmosphere of mixed $\mathrm{SF}_{6}$ and $\mathrm{CO}_{2}$. The molten metals were poured into preheated mild steel molds at $720{ }^{\circ} \mathrm{C}$ and quenched in water at ambient temperature. The samples for microstructure observation and corrosion property characterization were cut by wire cut electrical discharge machining from the as-cast ingot.

The differential scanning calorimeter (DSC, Netzsch STA 449 F3) was utilized to analyze the phase transition temperatures and melting point of the as-cast alloy. The test was carried out under an argon protective atmosphere, and the temperature ranged from 25 to $650{ }^{\circ} \mathrm{C}$ at a heating rate of $10^{\circ} \mathrm{C} / \mathrm{min}$. The DSC curve of the as-cast $\mathrm{Mg}-4 \mathrm{Gd}-$ $1 \mathrm{Y}-1 \mathrm{Zn}-0.5 \mathrm{Ca}-1 \mathrm{Zr}$ alloy is shown in Fig. 1. It is found that two endothermic peaks at 470 and $505{ }^{\circ} \mathrm{C}$, respectively, represent two phase transition temperatures of the alloy, and the melting point is observed at $646{ }^{\circ} \mathrm{C}$.

Based on the DSC result, the solution temperatures of the as-cast alloy were controlled to be 440,480 and $520{ }^{\circ} \mathrm{C}$, respectively. The as-cast specimens were ground with sandpaper and then solution-treated under a protective $\mathrm{SO}_{2}$ atmosphere for $6 \mathrm{~h}$ following by cooling in water at ambient temperature. The as-cast and solution-treated alloys were labeled as F, T4-440, T4-480 and T4-520, respectively. The specimens were ground progressively and polished using $3.5 \mu \mathrm{m} \mathrm{Al}_{2} \mathrm{O}_{3}$ suspension and then etched by 4 vol\% nitric acid in ethanol. The microstructures and phase compositions of the alloys were analyzed by using a scanning electron microscope (SEM, JSM-

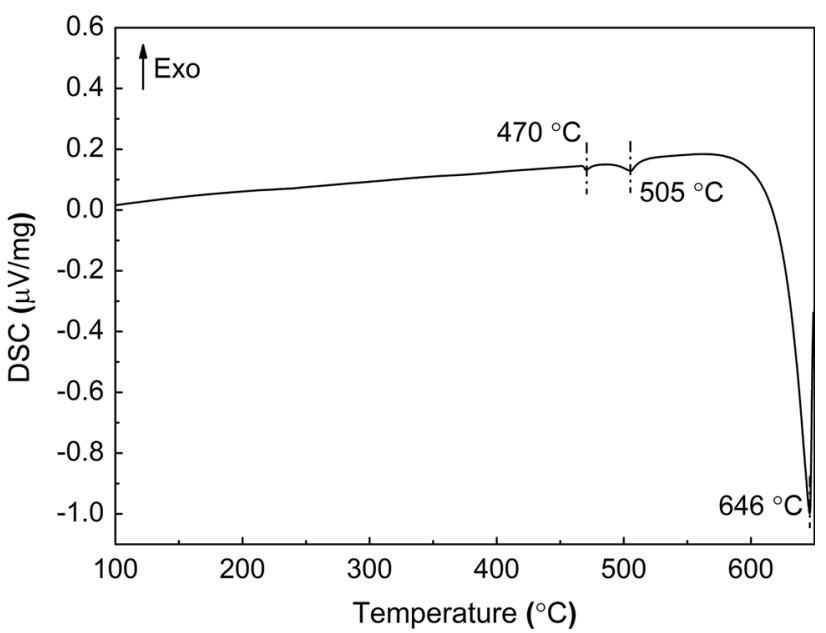

Fig. 1 DSC curve of the as-cast $\mathrm{Mg}-4 \mathrm{Gd}-1 \mathrm{Y}-1 \mathrm{Zn}-0.5 \mathrm{Ca}-1 \mathrm{Zr}$ alloy 
6360LV) equipped with an energy-dispersive spectrometer (EDS, GENESIS 2000XM60). An X-ray diffraction (XRD, Rigaku Ultima-IV) was used to identify the phase constitution of the alloys at a voltage of $40 \mathrm{kV}$ and a scanning rate of $10^{\circ} / \mathrm{min}$, and $2 \theta$ ranged from $20^{\circ}$ to $80^{\circ}$.

Four parallel samples with dimension of $\Phi$ $14.5 \mathrm{~mm} \times 3.5 \mathrm{~mm}$ were polished and immersed in $3.5 \%$ $\mathrm{NaCl}$ solution at ambient temperature according to ASTM G31. And the total immersion time was $60 \mathrm{~h}$. The hydrogen evolution volume was recorded, and the $\mathrm{NaCl}$ solution was renewed every $12 \mathrm{~h}$. After immersion test, the corroded specimens were cleaned in boiling chromic acid solution $\left(200 \mathrm{~g} / \mathrm{L} \mathrm{CrO}_{3}\right)$ to remove the corrosion products. The average mass loss was then obtained and utilized to calculate the corrosion rates of the alloys.

The corrosion properties of the samples were also characterized by electrochemical tests using an electrochemical workstation (Ametek PARSTAT 2273). The potentiodynamic polarization curves were measured in a standard three-electrode configuration, using the specimen as a working electrode with $1 \mathrm{~cm}^{2}$ exposed surface, the saturated calomel electrode (SCE) as a reference electrode and the platinum flake as counter electrode. Polarization tests at ambient temperature were carried out in $3.5 \% \mathrm{NaCl}$ solution at a scanning rate of $0.5 \mathrm{mV} / \mathrm{s}$.

\section{Results and Discussion}

\subsection{Microstructure}

The microstructures of the as-cast and solution-treated alloys are depicted in Fig. 2. The as-cast alloy mainly consists of bright $\alpha$-Mg matrix, gray block-shaped eutectic phases located at grain boundaries, accompanying with lamellar structures. As presented in Fig. 2b, the dense lamellar structures are observed at the outer edge of grain boundaries in the T4-440 alloy. Furthermore, it is found that the tiny precipitated particles are accumulated within the $\alpha-\mathrm{Mg}$ matrix. With the increase in the solution temperature, the eutectic phase vanishes nearly, and the $\alpha-\mathrm{Mg}$ matrix and fine precipitated phases are recognized as the main phases of the T4-480 and T4-520 alloys. Moreover, the T4-480 alloy exhibits no obvious difference in the grain size compared with the T4-440 alloy, but partly significant grain growth has been obtained for the alloy solutiontreated at $520{ }^{\circ} \mathrm{C}$; in particular, the grain boundaries of the alloy tend to be straight.

Figure 3 presents the SEM image of the as-cast alloy with high magnification, and EDS-analyzed results of the various areas marked in Fig. 3 are listed in Table 1. The local microstructures, including the gray $\alpha-\mathrm{Mg}$ matrix, bright block-shaped eutectic phase and lamellar structure, are shown more clearly. The lamellar structures exhibit the single orientation within each grain, while various orientations in different grains are recognized as the LPSO structure in both $\mathrm{Mg}-\mathrm{Y}-\mathrm{Zn}[31,32,41,42]$ and $\mathrm{Mg}-\mathrm{Gd}-$ $\mathrm{Zn}$ [33-35, 46] systems. Combined with the EDS results, it is found that the contents of $\mathrm{Gd}, \mathrm{Y}$ and $\mathrm{Zn}$ in the lamellar structure are higher than those in the $\alpha-\mathrm{Mg}$ matrix, but less than those in the eutectic phases. The $\mathrm{Gd}, \mathrm{Y}, \mathrm{Zn}$ and $\mathrm{Ca}$ concentrations of the phase marked as the region $\mathrm{A}$ are the highest among the phases, followed by the region $\mathrm{B}$. But the morphologies between these two regions show visible difference; specifically, the phase denoted as the area B exhibits lamellar and stacking microstructure, inferred as the LPSO structure. Previous investigation has also found that the LPSO structure could exist in the eutectic phase of the $\mathrm{Mg}-\mathrm{Zn}-\mathrm{Y}-\mathrm{Gd}$ alloy, which was mainly because the requirement of $\mathrm{RE} / \mathrm{Zn}$ atomic ratio was satisfied and caused by the dissolution of $\mathrm{Zn}$ [42]. Nevertheless, the inexistence of the LPSO structure in the region A may be influenced by the $\mathrm{Zn}$ concentration. The lowest $\mathrm{Ca}$ content is detected in the $\alpha$-Mg matrix, and the Zr-rich particles (e.g., marked as E) are observed within the $\alpha$-Mg grain in the as-cast alloy.

In order to further clarify the microstructure and composition evolutions of the alloys after solution treatment, the SEM images were obtained and the various regions of the alloys were analyzed by EDS, as shown in Fig. 4 and Table 2, respectively. The LPSO structure at the grain boundary, marked as the region B, is still observed for T4440 alloy, where the lower Gd and Y contents but the higher concentrations of other elements are detected in comparison with the as-cast alloy. With the increase in the solution temperature, the volume fraction of the eutectic phase decreases markedly, and the precipitated phases where $\mathrm{Zr}$ element is more highly concentrated appear within the $\alpha-\mathrm{Mg}$ matrix for T4-480 and T4-520 alloys. In addition, the $\mathrm{Zr}$ content of the region $\mathrm{E}$ in Fig. $4 \mathrm{~b}$ is lower compared with the region $\mathrm{H}$ in Fig. 4c. The $\mathrm{Ca}$ element is distributed homogeneously after solution treatment, and the higher solution temperature contributes to the total content increase in all the alloying elements in the $\alpha-\mathrm{Mg}$ matrix.

The XRD patterns of the Mg-4Gd-1Y-1Zn-0.5Ca-1Zr alloy are shown in Fig. 5. Besides $\alpha-\mathrm{Mg}$ solid solutions, $\mathrm{Mg}_{12}(\mathrm{Gd}, \mathrm{Y}) \mathrm{Zn}$ and $\mathrm{Mg}_{24}(\mathrm{Gd}, \mathrm{Y}, \mathrm{Zn})_{5}$ phases are detected. The diffraction peaks of $\alpha-\mathrm{Mg}$ and $\mathrm{Mg}_{12}(\mathrm{Gd}, \mathrm{Y}) \mathrm{Zn}$ phases identified in the XRD spectra are approximately consistent with $\mathrm{Mg}-\mathrm{Zn}-\mathrm{Y}(-\mathrm{Gd})$ alloys investigated by Shi et al. [41] and Zhang et al. [42], and the $\mathrm{Mg}_{12} \mathrm{ZnRE}$ phases detected in these references are also recognized as 14H-LPSO structure. Moreover, it seems that the intensity of $\operatorname{Mg}_{12}(-$ Gd,Y)Zn phase shows no significant difference between $\mathrm{F}$ and T4-440 alloys but the diffraction peak of this phase is not detected with further increase in the solution temperature, in response to the microstructural evolution of the 

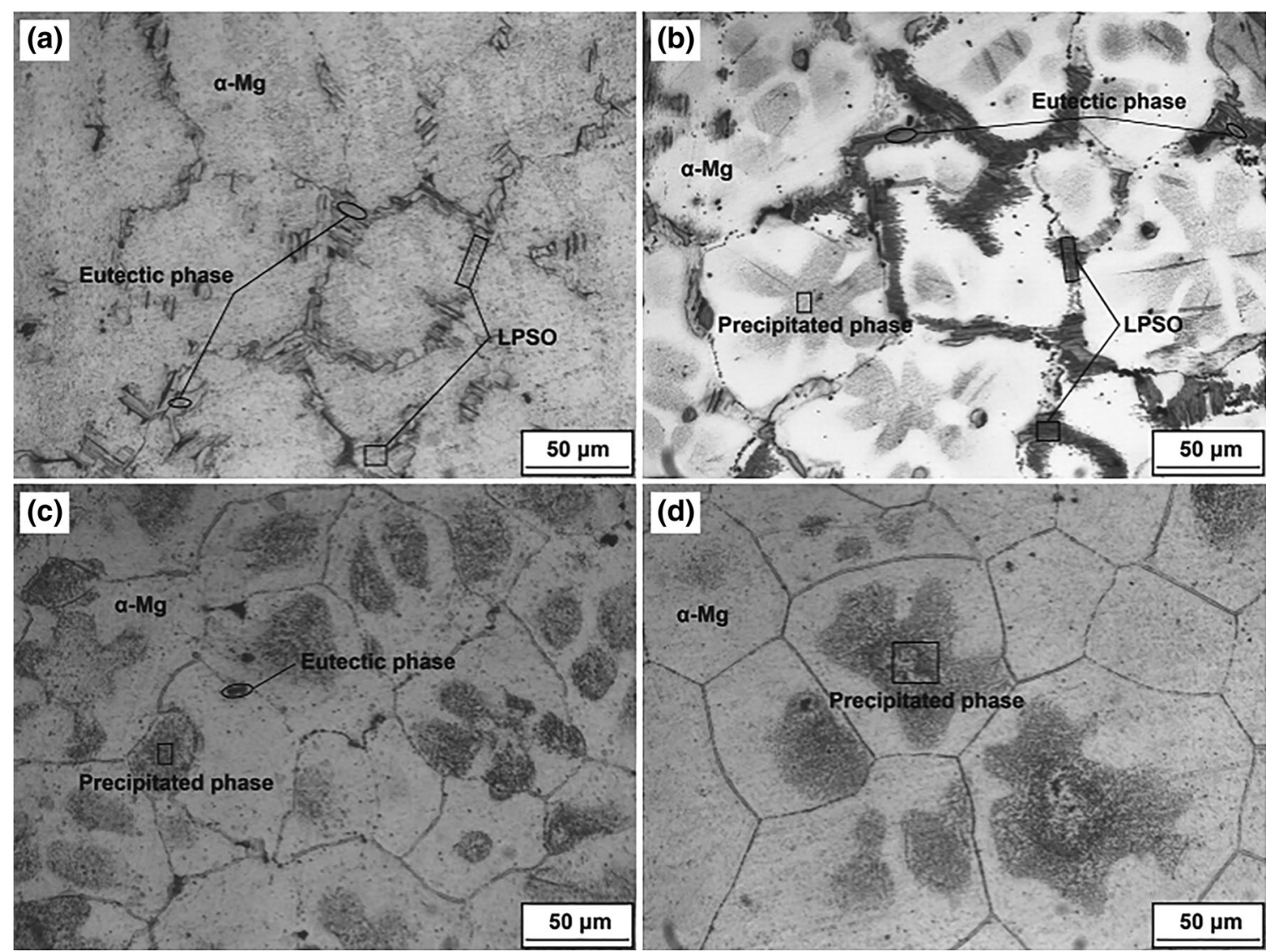

Fig. 2 Optical microstructures of the $\mathrm{Mg}-4 \mathrm{Gd}-1 \mathrm{Y}-1 \mathrm{Zn}-0.5 \mathrm{Ca}-1 \mathrm{Zr}$ alloy under different conditions: a F, b T4-440, c T4-480, d T4-520

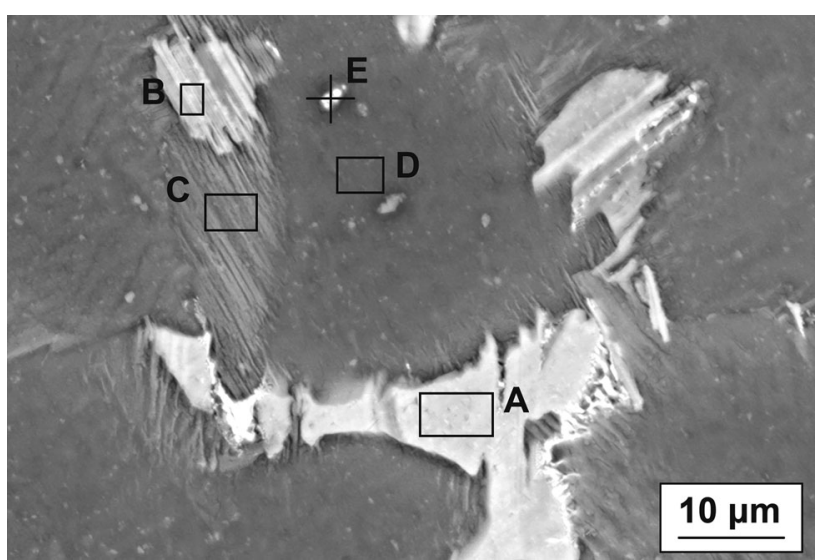

Fig. 3 SEM image of the as-cast alloy with high magnification

alloys under different conditions. It has been previously reported that $\mathrm{Mg}_{24} \mathrm{Y}_{5}$ intermetallic compound is a kind of secondary phases in the $\mathrm{Mg}-\mathrm{Y}-\mathrm{Gd}, \mathrm{Mg}-\mathrm{Y}-\mathrm{Zn}$ and $\mathrm{Mg}-\mathrm{Y}-$ $\mathrm{Zr}$ series alloys [27, 47-49]. In this work, the diffraction peaks of $\mathrm{Mg}_{24}(\mathrm{Gd}, \mathrm{Y}, \mathrm{Zn})_{5}$ exist in the as-cast, T4-440 and T4-480 alloys, while they are invisible for the alloy solution-treated at $520{ }^{\circ} \mathrm{C}$ due to the low amount of the eutectic phase.
Table 1 EDS-analyzed results of the various areas marked in Fig. 3 (wt\%)

\begin{tabular}{llrlrlr}
\hline Area & $\mathrm{Mg}$ & \multicolumn{1}{l}{$\mathrm{Gd}$} & $\mathrm{Y}$ & \multicolumn{1}{l}{$\mathrm{Zn}$} & $\mathrm{Ca}$ & \multicolumn{1}{c}{$\mathrm{Zr}$} \\
\hline A & 60.63 & 23.89 & 2.39 & 10.04 & 1.75 & 1.30 \\
B & 69.20 & 20.90 & 1.71 & 6.79 & 1.23 & 0.17 \\
C & 88.84 & 8.81 & 0.77 & 0.98 & 0.23 & 0.37 \\
D & 96.53 & 1.72 & 0.26 & 0.51 & 0.07 & 0.89 \\
E & 42.46 & 3.65 & 0 & 1.23 & 0.34 & 52.32 \\
\hline
\end{tabular}

In general, according to the microstructure evolution of the alloy, it is summarized that the volume fraction of the eutectic phase decreases while that of the precipitated phase increases. The LPSO structure increases first and vanishes with the increase in the solution temperature. In addition, the partly increased grain size is found in the T4520 alloy and most grains are equiaxed. The EDS results indicate that the concentrations of $\mathrm{Gd}, \mathrm{Y}, \mathrm{Zn}$ and $\mathrm{Ca}$ elements in the eutectic phase decrease after solution treatment as compared to that of the as-cast alloy; however, the higher contents of those elements in the $\alpha$-Mg matrix are detected. Therefore, it means that these alloying elements are diffused into the $\alpha-\mathrm{Mg}$ matrix under thermodynamics 

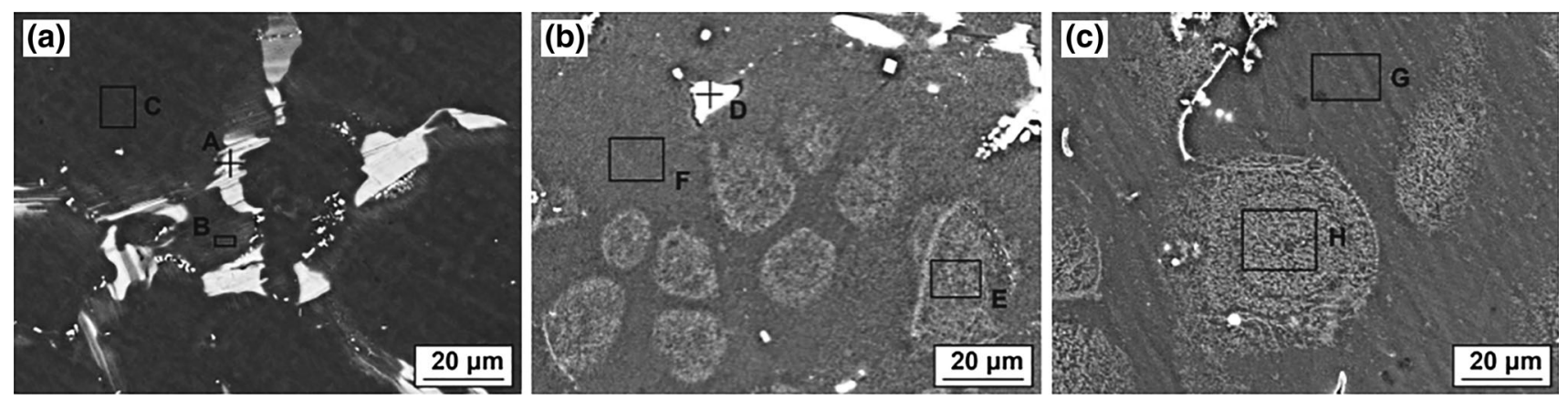

Fig. 4 SEM images of the solution-treated alloys: a T4-440, b T4-480, c T4-520

Table 2 Chemical composition (wt $\%$ ) of the various areas marked in Fig. 4

\begin{tabular}{lllrllll}
\hline Alloy & Area & $\mathrm{Mg}$ & \multicolumn{1}{l}{$\mathrm{Gd}$} & $\mathrm{Y}$ & $\mathrm{Zn}$ & $\mathrm{Ca}$ & $\mathrm{Zr}$ \\
\hline T4-440 & A & 71.73 & 18.27 & 2.02 & 7.06 & 0.48 & 0.44 \\
& $\mathrm{~B}$ & 89.05 & 6.50 & 0.71 & 2.07 & 0.71 & 0.96 \\
& $\mathrm{C}$ & 94.17 & 3.33 & 0.96 & 0.67 & 0.48 & 0.38 \\
& $\mathrm{D}$ & 68.00 & 19.98 & 2.82 & 8.22 & 0.52 & 0.46 \\
$\mathrm{~T} 4-480$ & $\mathrm{E}$ & 90.26 & 4.52 & 0.84 & 1.85 & 0.43 & 2.10 \\
& F & 91.50 & 4.92 & 0.82 & 1.28 & 0.60 & 0.88 \\
& $\mathrm{G}$ & 92.29 & 5.34 & 0.31 & 1.53 & 0.40 & 0.12 \\
$\mathrm{~T} 4-520$ & $\mathrm{H}$ & 87.59 & 4.89 & 0.17 & 2.78 & 0.55 & 4.02 \\
& & & & & & &
\end{tabular}

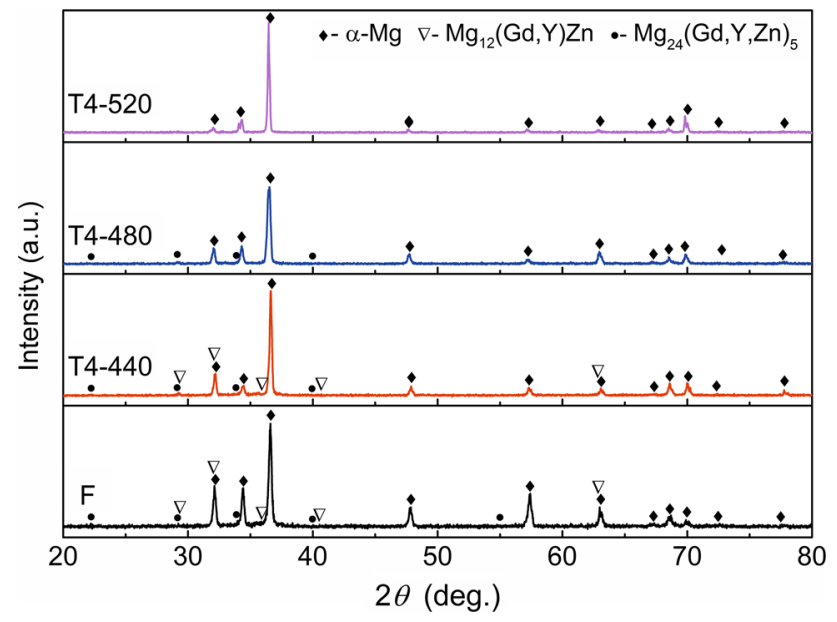

Fig. $5 \mathrm{XRD}$ patterns of the $\mathrm{Mg}-4 \mathrm{Gd}-1 \mathrm{Y}-1 \mathrm{Zn}-0.5 \mathrm{Ca}-1 \mathrm{Zr}$ alloy

driving force. The Zr-rich precipitated phase appears after solution treatment, and the volume fraction increases.

It has been found that the LPSO structure exists in the $\mathrm{Mg}$ alloy with high $\mathrm{Gd}$ and $\mathrm{Y}$ contents [30]. In this work, the LPSO structure is found in the as-cast $\mathrm{Mg}-4 \mathrm{Gd}-1 \mathrm{Y}-$ $1 \mathrm{Zn}-0.5 \mathrm{Ca}-1 \mathrm{Zr}$ alloy with $5 \%$ total addition of $\mathrm{Gd}$ and $\mathrm{Y}$ elements. It has been reported that stacking faults were formed first during the cooling process of the
$\mathrm{Mg}_{96.82} \mathrm{Gd}_{2} \mathrm{Zn}_{1} \mathrm{Zr}_{0.18}$ alloy, since the normal lattice locations of $\mathrm{Mg}, \mathrm{Zn}$ and $\mathrm{Gd}$ atoms were deflected. And when other requirements including the composition and stacking orders as well as the thermodynamic and dynamic requirements were satisfied, the LPSO structure was formed [46]. As presented in Figs. 3 and 4, the LPSO structure in the as-cast and T4-440 alloys is formed in the vicinity of the eutectic phase, where the $\mathrm{Gd}, \mathrm{Y}$ and $\mathrm{Zn}$ concentrations are rich according to Tables 1 and 2. The XRD analysis has revealed that the LPSO structure is identified as $\operatorname{Mg}_{12}(\mathrm{Gd}, \mathrm{Y}) \mathrm{Zn}$ phase, roughly consistent with 14H-LPSO structure in Refs. [41, 42]. The thermodynamic requirement is satisfied after solution treatment at $440{ }^{\circ} \mathrm{C}$, and near the eutectic phase, the volume fraction of the LPSO structure increases. However, with the increase in solution temperature, the alloying elements are further dissolved into the $\alpha-\mathrm{Mg}$ matrix, resulting in the disappearance of the LPSO structure and the formation of the precipitated phase.

\subsection{Corrosion Properties}

The corrosion properties of the alloys were evaluated by immersion test in $3.5 \% \mathrm{NaCl}$ solution for $60 \mathrm{~h}$, and the corrosion rates calculated by mass loss and $\mathrm{H}_{2}$ evolution, respectively, are plotted in Fig. 6. The as-cast alloy shows the highest corrosion rate among the alloys. After solution treatment, the corrosion resistance of the alloys is enhanced significantly. With the increase in the solution temperature, the corrosion rate decreases first and then increases, following the order: F $>$ T4-520 $>$ T4-440 $>$ T4-480, meaning that the T4-480 alloy exhibits the best corrosion resistance. It is noticeable that the corrosion rates calculated by mass loss are higher than those calculated by $\mathrm{H}_{2}$ evolution for the all alloys. This can be explained as follows. During the immersion process, some hydrogen released into the air when renewing $\mathrm{NaCl}$ solution, and some will be dissolved into the immersion solution [50]. Additionally, peeling off the eutectic phase caused by the 


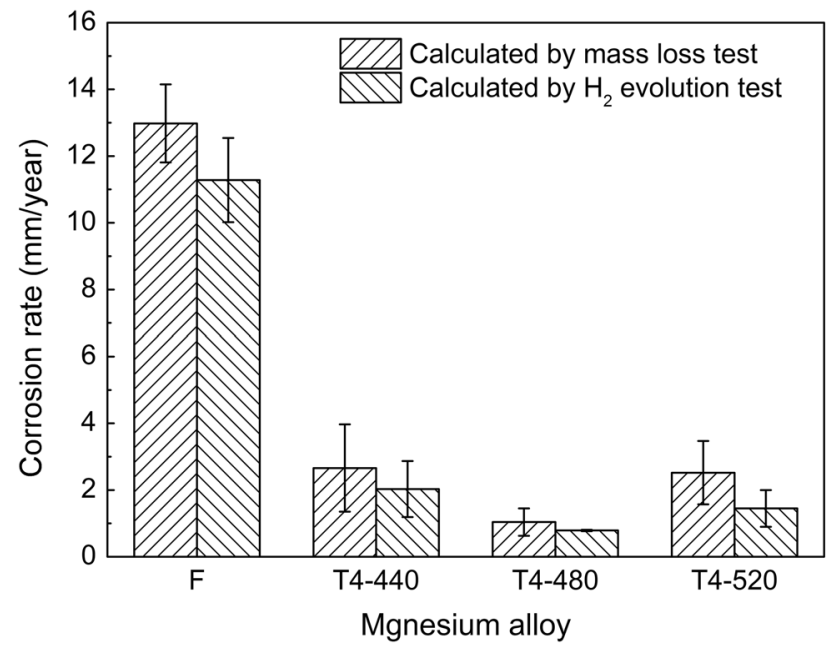

Fig. 6 Corrosion rates of the alloys immersed in $3.5 \% \mathrm{NaCl}$ solution

chromic acid during the cleaning process accounts for the larger mass loss.

Figure 7 presents the polarization curves of the alloys tested in $3.5 \% \mathrm{NaCl}$ solution, and the fitting results obtained by Tafel extrapolation are listed. The current density of the alloy under different conditions presents the following trend: T4-480 $<\mathrm{F}<\mathrm{T} 4-440<\mathrm{T} 4-520$. Because the lower current density means the better corrosion resistance from the perspective of corrosion kinetics, the T4-480 alloy exhibits the best corrosion resistance but the T4-520 alloy shows a negative corrosion property. The polarization results are not in complete agreement with the immersion results. Nevertheless, based on the corrosion process, the immersion tests reveal a long-term corrosion rate of the alloy while the potentiodynamic polarization tests reflect an instant corrosion resistance of the alloys $[51,52]$. Therefore, the corrosion rate calculated by mass

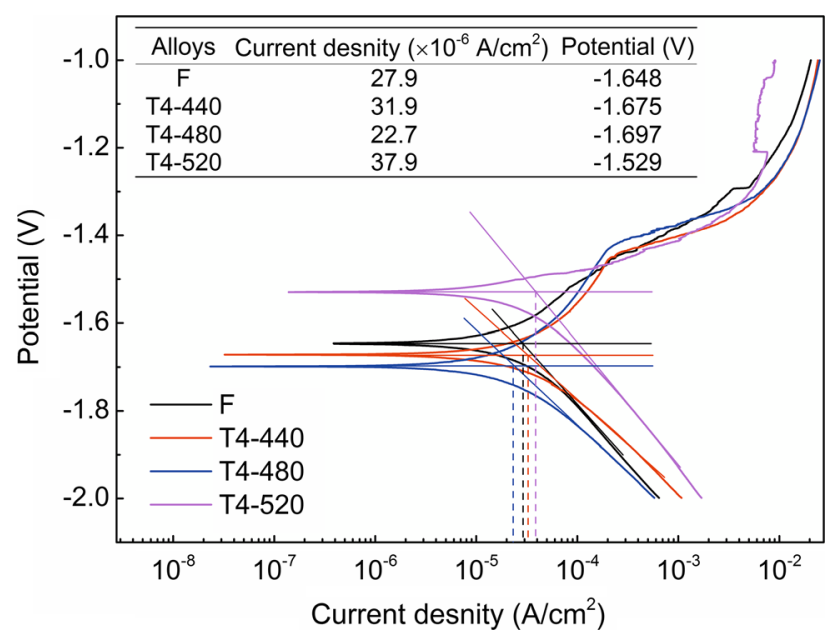

Fig. 7 Polarization curves of the alloys tested in $3.5 \% \mathrm{NaCl}$ solution loss and $\mathrm{H}_{2}$ evolution is more convincible than that evaluated by electrochemical test.

Recent study has revealed that the corrosion rate of ascast $\mathrm{Mg}_{95} \mathrm{Y}_{2} \mathrm{Zn}_{1} \mathrm{Gd}_{2}$ alloy calculated by mass loss in $3 \%$ $\mathrm{NaCl}$ solution was about $756.78 \mathrm{~mm} /$ year, and the fast corrosion was mainly ascribed to the large volume fraction of eutectic phase [42]. The as-cast $\mathrm{Mg}_{94} \mathrm{Zn}_{3} \mathrm{Y}_{1.5} \mathrm{Gd}_{1.5}$ alloy, with the largest volume fraction of LPSO phase among the investigated $\mathrm{Mg}$ alloys, exhibited high corrosion current density of $63.52 \times 10^{-6} \mathrm{~A} / \mathrm{cm}^{2}$ in $3.5 \% \mathrm{NaCl}$ solution [41]. This was mainly because the galvanic corrosion was accelerated by the more alloying elements in $\alpha-\mathrm{Mg}$ and the second phases. It has also been reported that the corrosion rate of $\mathrm{Mg}-10 \mathrm{Gd}-3 \mathrm{Y}$ alloy immersed in $5 \% \mathrm{NaCl}$ solution reached more than $15 \mathrm{~mm} /$ year owing to the presence of the coarse and discontinuously distributed $\beta$-phase [53].

The immersion test results herein conclude that the corrosion rates of the T4-440, T4-480 and T4-520 alloys are $2.66,1.04$ and $2.52 \mathrm{~mm} /$ year, respectively, which are about $20.5 \%, 8.0 \%$ and $19.4 \%$ of that of the as-cast alloy, indicating that the solution treatment has a positive effect on the corrosion properties of the $\mathrm{Mg}-4 \mathrm{Gd}-1 \mathrm{Y}-1 \mathrm{Zn}$ $0.5 \mathrm{Ca}-1 \mathrm{Zr}$ alloy. And the corrosion properties of all the alloys under different conditions obtained are better than those of the $\mathrm{Mg}$ alloys mentioned in the above references. It has been found that the LPSO structure has a dual effect on the corrosion resistance of the $\mathrm{Mg}$ alloys. On the one hand, the LPSO structure can act as a barrier between the substrate and eutectic phase, and hence, the corrosion is weakened and the substrate is effectively protected [54]. On the other hand, the presence of $\mathrm{Mg}_{12} \mathrm{YZn}$ phase (LPSO) in the $\mathrm{Mg}-\mathrm{Zn}-\mathrm{Y}$ alloys accelerates the galvanic corrosion of the $\alpha-\mathrm{Mg}$ matrix, and the corrosion rate of the alloy is controlled by the morphology and volume fraction of the LPSO structure [55]. Generally, the potential of the $\alpha-\mathrm{Mg}$ matrix is more negative than the LPSO structure, eutectic phase and precipitated phase. The $\alpha-M g$ matrix suffers from preferential corrosion since it acts as the anode when immersed in the corrosive medium. According to schematic diagrams of corrosion process reported in Ref. [54], and based on the microstructure and composition changes of the $\mathrm{Mg}-4 \mathrm{Gd}-1 \mathrm{Y}-1 \mathrm{Zn}-0.5 \mathrm{Ca}-1 \mathrm{Zr}$ alloy under different conditions, the bared $\alpha-\mathrm{Mg}$ matrix in the as-cast and T4440 alloys undergoes the corrosion first and then the transitional LPSO structure is corroded, which is more corrosion resistant than the $\alpha-\mathrm{Mg}$ matrix. Therefore, the further corrosion of the $\alpha-\mathrm{Mg}$ matrix in the T4-440 alloy can be hindered to a certain extent, due to the barrier effect of the more LPSO structure volume fraction compared with the as-cast alloy. The $\mathrm{Zr}$-rich particles observed within the $\alpha$-Mg matrix in the as-cast alloy are also recognized as the detrimental factors to the corrosion property. Furthermore, the T4-440 alloy exhibits better corrosion resistance than 
the as-cast alloy owing to the uniform distribution of the alloying elements caused by the solution treatment. However, the T4-440 alloy is more sensitive to the corrosion than the T4-480 alloy. Therefore, it seems that the good corrosion resistance is ascribed not only to the LPSO structure but also to the other impacts. During the solution treatment process, the $\mathrm{Gd}, \mathrm{Y}, \mathrm{Zn}$ and $\mathrm{Ca}$ elements are gradually diffused into the $\alpha-\mathrm{Mg}$ matrix, and hence, the potential difference between those phases and the $\alpha-M g$ matrix is balanced. The galvanic corrosion is weakened in the T4-440 and T4-480 alloys. As presented in Fig. 2c, the eutectic phase nearly disappears, resulting in the reduction in galvanic couples. And the corrosion property of T4-480 alloy is further improved. With the further increase in the solution temperature, the volume fraction of the precipitated phase increases and the $\mathrm{Zr}$ concentration of this phase is enhanced; as a result, the galvanic corrosion is strengthened again. Therefore, the T4-520 alloy exhibits higher corrosion rate than the T4-480 alloy.

\section{Conclusions}

1. The as-cast $\mathrm{Mg}-4 \mathrm{Gd}-1 \mathrm{Y}-1 \mathrm{Zn}-0.5 \mathrm{Ca}-1 \mathrm{Zr}$ alloy is composed of the $\alpha-\mathrm{Mg}$ matrix, eutectic phases and LPSO structure. After solution treatment, the LPSO structure increases first and then vanishes. The volume fraction of the eutectic phases decreases, and that of the precipitated phases increases gradually with the increase in the solution temperature.

2. The $\alpha-M g$ solutions, $\operatorname{Mg}_{12}(\mathrm{Gd}, \mathrm{Y}) \mathrm{Zn}$ and $\mathrm{Mg}_{24}(-$ $\mathrm{Gd}, \mathrm{Y}, \mathrm{Zn})_{5}$ are identified as the main phases of the alloys, and $\mathrm{Mg}_{12}(\mathrm{Gd}, \mathrm{Y}) \mathrm{Zn}$ phase represents the LPSO structure.

3. The corrosion rate of the alloys decreases first and then increases slightly with the increase in the solution temperature. The as-cast $\mathrm{Mg}-4 \mathrm{Gd}-1 \mathrm{Y}-1 \mathrm{Zn}-0.5 \mathrm{Ca}-$ $1 \mathrm{Zr}$ alloy shows good corrosion resistance, and the solution treatment further enhances the corrosion property of the alloy. In addition, the T4-480 alloy presents the best corrosion resistance for its corrosion rate which is reduced by $92 \%$ as compared to the ascast alloy.

Acknowledgements This work was financially supported by the Natural Science Foundation of Jiangsu Province for Outstanding Youth (No. BK20160081), the Innovative Foundation Project for Students of Nanjing Institute of Technology (No. TP20170011), the Six Talent Peaks of Jiangsu Province (No. 2015-XCL-025) and the Outstanding Scientific and Technological Innovation Team in Colleges and Universities of Jiangsu Province.

\section{References}

[1] M. Esmaily, J.E. Svensson, S. Fajardo, N. Birbilis, G.S. Frankel, S. Virtanen, R. Arrabal, S. Thomas, L.G. Johansson, Prog. Mater Sci. 89, 92 (2017)

[2] F.S. Pan, M.B. Yang, X.H. Chen, J. Mater. Sci. Technol. 32, 1211 (2016)

[3] D.D. Zhang, D.P. Zhang, F.Q. Bu, X.L. Li, K. Guan, Q. Yang, S.H. Liu, X.J. Liu, J. Meng, Mater. Sci. Eng. A 693, 51 (2017)

[4] Q.S. Yang, B. Jiang, Z.J. Yu, Q.W. Dai, S.Q. Luo, Acta Metall. Sin. (Engl. Lett.) 28, 1257 (2015)

[5] M.K. Kulekci, Int. J. Adv. Manuf. Technol. 39, 851 (2008)

[6] B. Pourbahari, H. Mirzadeh, M. Emamy, Mater. Sci. Eng. A 680, 39 (2017)

[7] Q.F. Qin, Y.X. Tan, Z.M. Zhang, Q. Wang, Y.B. Yang, J. Mater. Eng. Perform. 25, 304 (2016)

[8] G.L. Song, A. Atrens, Adv. Eng. Mater. 1, 11 (1999)

[9] S. Doja, L. Bichler, S. Fan, Acta Metall. Sin. (Engl. Lett.) 30, 367 (2017)

[10] K. Chen, J.W. Dai, X.B. Zhang, Corros. Rev. 33, 101 (2015)

[11] Q.S. Dong, Z.X. Ba, Z.Z. Wang, J. Kuang, Z.Y. Cai, C. Yuan, Acta Metall. Sin. (Engl. Lett.) 29, 993 (2016)

[12] X.J. Wang, D.K. Xu, R.Z. Wu, X.B. Chen, Q.M. Peng, L. Jin, Y.C. Xin, Z.Q. Zhang, Y. Liu, X.H. Chen, G. Chen, K.K. Deng, H.Y. Wang, J. Mater. Sci. Technol. http://dx.doi.org/10.1016/j. jmst.2017.07.019

[13] X.B. Zhang, Z.X. Ba, Z.Z. Wang, Y.J. Xue, Corros. Sci. 105, 68 (2016)

[14] M.B. Yang, M.D. Hou, J. Zhang, F.S. Pan, Trans. Nonferr. Met. Soc. China 24, 2497 (2014)

[15] B. Pourbahari, M. Emamy, H. Mirzadeh, Prog. Nat. Sci. 27, 228 (2017)

[16] A. Boby, A. Srinivasan, U.T.S. Pillai, B.C. Pai, Mater. Des. 88, 871 (2015)

[17] M. Mondet, E. Barraud, S. Lemonnier, J. Guyon, N. Allain, T. Grosdidier, Acta Mater. 119, 55 (2016)

[18] S.Z. Zhu, T.J. Luo, T.A. Zhang, Y.T. Liu, Y.S. Yang, Trans. Nonferr. Met. Soc. China 27, 73 (2017)

[19] T. Zhang, Y.W. Shao, G.Z. Meng, Z.Y. Cui, F.H. Wang, Corros. Sci. 53, 1960 (2011)

[20] Y.A. Chen, H. Liu, R.Y. Ye, G.Q. Liu, Mater. Sci. Eng. A 587, 262 (2013)

[21] T. Zhang, G.Z. Meng, Y.W. Shao, Z.Y. Cui, F.H. Wang, Corros. Sci. 53, 2934 (2011)

[22] F.Q. Bu, Q. Yang, X. Qiu, T. Zheng, D.P. Zhang, X.D. Niu, Y.D. Li, X.J. Liu, J. Meng, Mater. Sci. Eng. A 639, 198 (2015)

[23] C.J. Che, Z.Y. Cai, X.H. Yang, L.R. Cheng, Y.Q. Du, Mater. Sci. Eng. A 705, 282 (2017)

[24] N. Jiang, L. Chen, L.G. Meng, C.F. Fang, H. Hao, X.G. Zhang, J. Rare Earth 34, 632 (2016)

[25] F.Q. Bu, Q. Yang, K. Guan, X. Qiu, D.P. Zhang, W. Sun, T. Zheng, X.P. Cui, S.C. Sun, Z.M. Tang, X.J. Liu, J. Meng, J. Alloys Compd. 688, 1241 (2016)

[26] S. Huang, J.F. Wang, F. Hou, X.H. Huang, F.S. Pan, Mater. Sci. Eng. A 612, 363 (2014)

[27] H.R. Jafari Nodooshan, W.C. Liu, G.H. Wu, Y. Rao, C.X. Zhou, S.P. He, W.J. Ding, R. Mahmudi, Mater. Sci. Eng. A 615, 79 (2014)

[28] S.Q. Liang, D.K. Guan, X.P. Tan, Mater. Des. 32, 1194 (2011)

[29] Q. Yang, B.L. Xiao, D. Wang, M.Y. Zheng, K. Wu, Z.Y. Ma, J. Alloys Compd. 581, 585 (2013)

[30] Q.Z. Liu, X.F. Ding, Y.P. Liu, X.J. Wei, J. Alloys Compd. 690, 961 (2017)

[31] Y. Kawamura, K. Hayashi, A. Inoue, T. Masumoto, Mater. Trans. 42, 1172 (2001) 
[32] H. Liu, F. Xue, J. Bai, J. Zhou, Y.S. Sun, Acta Metall. Sin. 49, 236 (2013). (in Chinese)

[33] Y.J. Wu, X.Q. Zeng, D.L. Lin, L.M. Peng, W.J. Ding, J. Alloys Compd. 477, 193 (2009)

[34] J.S. Zhang, W.B. Zhang, X.Q. Ruan, L.P. Bian, W.L. Cheng, H.X. Wang, C.X. Xu, Mater. Sci. Eng. A 560, 847 (2013)

[35] X.B. Zhang, J.W. Dai, H.Y. Yang, S.Y. Liu, X.C. He, Z.Z. Wang, Mater. Technol. 32, 399 (2017)

[36] K. Yamada, Y. Okubo, M. Shiono, H. Watanabe, S. Kamado, Y. Kojima, Mater. Trans. 47, 1066 (2006)

[37] D.J. Li, X.Q. Zeng, J. Dong, C.Q. Zhai, W.J. Ding, J. Alloys Compd. 468, 164 (2009)

[38] Y.J. Wu, C. Xu, F.Y. Zheng, L.M. Peng, Y. Zhang, W.J. Ding, Mater. Charact. 79, 93 (2013)

[39] D.K. Xu, E.H. Han, Y.B. Xu, Prog. Mater Sci. 26, 117 (2016)

[40] Z.M. Li, D.Q. Wan, Y. Huang, S.T. Ye, Y.L. Hu, J. Magn. Alloys 5, 217 (2017)

[41] F. Shi, C.Q. Wang, Z.M. Zhang, Trans. Nonferr. Met. Soc. China 25, $2172(2015)$

[42] J.Y. Zhang, M. Xu, X.Y. Teng, M. Zuo, J. Magn. Alloys 4, 319 (2016)

[43] S.H. Cai, T. Lei, N.F. Li, F.F. Feng, Mater. Sci. Eng. C 32, 2570 (2012)
[44] J. Yang, J. Peng, M. Li, E.A. Nyberg, F.S. Pan, Acta Metall. Sin. (Engl. Lett.) 30, 53 (2017)

[45] H. Jafari, P. Amiryavari, Mater. Sci. Eng. A 654, 161 (2016)

[46] Y.J. Wu, D.L. Lin, X.Q. Zeng, L.M. Peng, W.J. Ding, J. Mater. Sci. 44, 1607 (2009)

[47] H. Liu, F. Xue, J. Bai, A.B. Ma, J.H. Jiang, J. Mater. Sci. Technol. 32, 1267 (2016)

[48] X.Y. Xu, X.H. Chen, W.W. Du, Y.X. Geng, F.S. Pan, J. Mater. Sci. Technol. 33, 926 (2017)

[49] J. Wu, Q. Shi, Y.L. Chiu, Mater. Charact. 129, 46 (2017)

[50] N.T. Kirkland, N. Birbilis, M.P. Staiger, Acta Biomater. 8, 925 (2012)

[51] X.B. Zhang, Q. Wang, Z.X. Ba, Z.Z. Wang, Y.J. Xue, J. Mater. Eng. Perform. 25, 719 (2016)

[52] X.B. Zhang, Z.X. Ba, Z.Z. Wang, Y.J. Xue, Q. Wang, Trans. Nonferr. Met. Soc. China 24, 3797 (2014)

[53] M. Sun, G.H. Wu, W. Wang, W.J. Ding, Mater. Sci. Eng. A 523, 145 (2009)

[54] X.B. Zhang, Z.X. Ba, Q. Wang, Y.J. Wu, Z.Z. Wang, Q. Wang, Corros. Sci. 88, 1 (2014)

[55] J.S. Zhang, J.D. Xu, W.L. Cheng, C.J. Chen, J.J. Kang, J. Mater. Sci. Technol. 28, 1157 (2012) 